\title{
A survey of risk tolerance to multiple sclerosis therapies
}

Robert J. Fox, MD, Carol Cosenza, MSW, Lauren Cripps, MA, Paul Ford, PhD, MaryBeth Mercer, MPH, Sneha Natarajan, PhD, Amber Salter, PhD, Tuula Tyry, PhD, and Stacey S. Cofield, PhD

Neurology ${ }^{\circledR}$ 2019;92:e1634-e1642. doi:10.1212/WNL.0000000000007245

\section{Abstract}

\section{Objective}

To determine tolerance to various risk scenarios associated with current multiple sclerosis (MS) therapies.

\section{Methods}

People with MS from the North American Research Committee on Multiple Sclerosis Registry's online cohort and the National Multiple Sclerosis Society were invited to complete a questionnaire on tolerance to real-world risks associated with a hypothetical therapy. Multiple risks levels were presented, including skin rash, infection, kidney injury, thyroid injury, liver injury, and progressive multifocal leukoencephalopathy (PML).

\section{Results}

Both PML and kidney injury had the lowest risk tolerance (RT) at 1:1,000,000, and thyroid and infection risks had the highest tolerance at 1:1,000. Men, younger individuals, and participants with greater disability reported a higher tolerance to all risk scenarios. Those who were currently taking an MS therapy reported higher tolerance than those not taking any therapy. Participants taking infusion therapies reported high tolerance to all risks, and those taking injectables reported a lower tolerance.

\section{Conclusion}

People with MS displayed a wide range of RT for MS therapies. Our study identified sex, age, disability, and current disease-modifying therapy use to be associated with RT.

\author{
Correspondence \\ Dr. Fox \\ foxr@ccf.org
}

\section{RELATED ARTICLE}

\section{Editorial}

Patient-perceived risks of MS DMTs: Problems of communication and risk management?

Page 647

From the Mellen Center for Multiple Sclerosis, (R.J.F., S.N.), Department of Bioethics (P.F.), and Department of Bioethics (M.M.), Cleveland Clinic, OH; Center for Survey Research (C.C., L.C.), University of Massachusetts, Boston; Division of Biostatistics (A.S.), Washington University School of Medicine, St. Louis, MO; Dignity Health (T.T.), St. Joseph's Hospital and Medical Center, Phoenix, AZ; and Department of Biostatistics (S.S.C.), School of Public Health, University of Alabama, Birmingham.

Go to Neurology.org/N for full disclosures. Funding information and disclosures deemed relevant by the authors, if any, are provided at the end of the article. 


\section{Glossary}

DMT = disease modifying therapy; MS = multiple sclerosis; NARCOMS = North American Research Committee on Multiple Sclerosis; NMSS = National Multiple Sclerosis Society; PDDS = Patient Determined Disease Steps; PML = progressive multifocal leukoencephalopathy; $\mathbf{R T}=$ risk tolerance.

Multiple sclerosis (MS) is an autoimmune disorder of the CNS that often leads to neurologic disability. ${ }^{1}$ Although there is no available cure for MS, the past 2 decades have witnessed a dramatic development in disease-modifying therapies (DMTs) that reduce MS relapse and delay disability. There are 15 approved therapies for MS treatment, each with its own established benefits and risks. The injectables were the first set of DMTs to be approved. They reduce annualized clinical relapse rates by $\approx 30 \%$ and have low risks. ${ }^{2,3}$ Intravenously administered natalizumab is a highly effective DMT but carries a risk of progressive multifocal leukoencephalopathy (PML), an often fatal brain infection. ${ }^{4-8}$ Additional infusion and oral therapies with their own specific efficacy and safety profiles are available, with some also associated with PML risk.

An important aspect of the medical decision-making process for MS treatment is each individual's tolerance to the inherent risks associated with currently available DMTs. A few studies have assessed the risk tolerance (RT) of people with $\mathrm{MS}^{9,10}$ and have found that PML was regarded as an important concern by both people with MS and their clinicians. In an earlier study on RT, ${ }^{11}$ we found male sex and increased disability to be predictors of higher tolerance to 2 treatment scenarios: natalizumab and a hypothetical treatment that cured MS. While this study compared only 2 treatment scenarios, one being hypothetical, a direct comparison of the tolerance to not just PML but other risks associated with various DMTs has not been made. It is not known how RT to individual risks would influence treatment preference. In light of the increasing number of DMTs with a wide range of risks, we expanded on our initial study ${ }^{11}$ to explore RT to 6 real-world risks that are associated with current DMTs: skin rash, infection, kidney injury, thyroid injury, liver injury, and PML.

\section{Methods}

\section{Focus group}

Focus groups involving people with MS and their care partners were conducted at 4 geographically distant MS clinics across the United States to gain insights into factors related to their preferences while choosing an MS DMT. Focus groups were structured using a moderator guide to understand values and perceptions of living with MS and considerations when making decisions about MS therapies. Discussions were facilitated by an experienced moderator and audio recorded for data capture. Data analysis was an iterative and progressive process of data immersion, open coding, constant comparison, documentation, and theme identification.

\section{Survey design and testing}

Survey questions on DMT risk preferences and decision making were designed to incorporate the themes that emerged from the focus groups. Semistructured in-person cognitive interviews were conducted with 6 people with MS with diverse MS history to test the instrument for clarity and comprehension.

The survey was finalized on the basis of the findings from the cognitive interviews. In the final survey, individual risk preference and acceptance were evaluated by describing a hypothetical therapy with a fixed benefit of $50 \%$ reduction in clinical relapse rate and $30 \%$ reduction in disability progression. This efficacy is in the range of efficacy reported for the majority of currently used MS therapies. Using a single efficacy and varying only the types of risks reduced survey burden and potential confusion by participants. A standard gamble paradigm ${ }^{12,13}$ was used to evaluate the RT to each of the 6 risks. The risks were described as follows: (1) risk of infection such as bladder and respiratory, which may occasionally require hospitalization; (2) thyroid injury, which may require lifelong thyroid medication; (3) skin rash, which may be serious enough to require hospitalization; (4) liver injury, which may require repeated blood test monitoring; (5) kidney injury, which may require lifelong dialysis; and (6) risk of PML, which could be fatal. For each of the 6 risks, the odds of that risk were changed iteratively to identify the maximum RT for each risk for each participant. The survey was reviewed and approved by the Institutional Review Board at the University of Alabama at Birmingham.

\section{Survey administration}

The North American Research Committee on Multiple Sclerosis (NARCOMS) Registry maintains a global longitudinal database of confidential information voluntarily submitted by $>38,000$ people with MS. In 2010 and 2011, we had used the registry for a survey on patient decision making and RT. All 3,755 active NARCOMS Registry participants who had participated in either or both of the earlier surveys were invited via e-mail to participate in the new RT survey. The survey ran from March 3, 2016, to April 8, 2016. NARCOMS participants received up to 2 reminder e-mails to complete the survey. In addition, a link to the survey was available between March 17, 2016, and April 16, 2016, through the National Multiple Sclerosis Society (NMSS) website for anyone with MS who wished 
to participate in the survey. To avoid overlap between NMSS and NARCOMS participants, NMSS participants who indicated to also be a NARCOMS registrant were asked to complete the survey through the NARCOMS link. For both NARCOMS- and NMSS-administered surveys, online consent was obtained before survey administration, and NARCOMS staff were available via telephone and e-mail throughout the survey period to assist study participants.

A preset iterative algorithm was used to identify the maximum RT for each participant (figure 1). The lowest anchor point was 0 (never take any risk for the benefit), and the highest was 1 (will take any risk for the benefit). The survey collected demographic characteristics, socioeconomic information, DMT use, and disease characteristics, including disability measured with the Patient Determined Disease Steps (PDDS). ${ }^{14}$

\section{Statistical analysis}

To be included in the analysis, participants were required to have answered questions about their sex, disease duration, and PDDS and at least 4 of the 6 risk scenario questions. Missing data were left missing and were not imputed. Descriptive statistics were used to summarize demographic and RT results. Comparison of median RT used unadjusted Wilcoxon-Kruskal-Wallis test, with nonparametric multiple-comparisons test using the SteelDwass-adjusted method. Comparison of proportions used likelihood ratio $\chi^{2}$ or Fisher exact test, as applicable. To compare risk levels according to DMT type, DMTs were classified as injectable (daclizumab, glatiramer acetate, interferon beta- $1 \mathrm{a} / 1 \mathrm{~b}$, peginterferon beta-1a), oral (dimethyl fumarate, fingolimod, laquinimod, teriflunomide), or infusion (alemtuzumab, mitoxantrone, natalizumab). To determine risk levels adjusted for sex, age group, disability level, and current DMT status, participants' RT was allocated to willingness to accept large (RT 1:50, regardless of death), moderate (RT 1:1,000-1:100), low (RT 1: 50,000-1:2,000), or minimal (no risk, 1:100,000) risk for each condition and evaluated with an ordinal logistic regression. JMP Pro 12/13 (SAS Institute, Inc, Cary, NC) was used for analysis, and values of $p<0.05$ were considered meaningful.

\section{Data availability}

Because of ongoing data analyses, the raw data are currently not available. Interested qualified investigators should direct inquiries to the corresponding author.

\section{Results}

\section{Focus groups}

Thirty-six people with MS and 24 care partners participated in 8 focus groups. Of those with MS, 75\% were female, $81 \%$ were white, mean age was 53 years, 50\% were employed, and 39\% received disability insurance. The majority of support partners

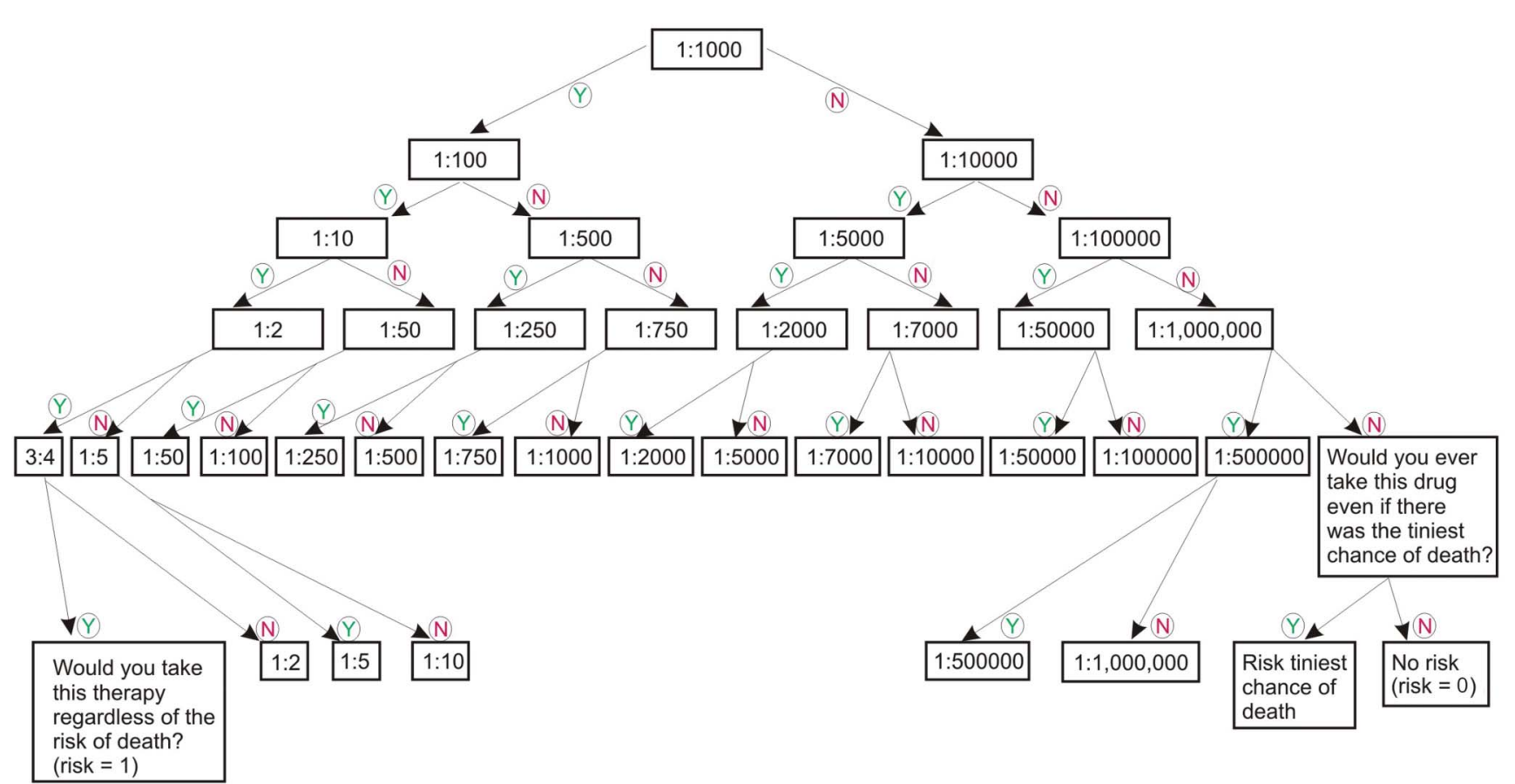

Risk levels used to evaluate the risk tolerance (RT) of study participants to various therapeutic scenarios, starting at 1:1,000. Participants would answer yes (Y) or no $(\mathrm{N})$ to incremental or decreasing risk levels on the basis of prior responses. An RT value was assigned at the last acceptable risk level indicated with a "yes." 
Table Respondent sociodemographic and disease characteristics

\begin{tabular}{|c|c|c|}
\hline Characteristics & All & DMT current \\
\hline No. (\%) & $3,371(100)$ & $1,798(53.5)$ \\
\hline Age, mean (SD), $y^{a}$ & $55.1(11.1)$ & $53.4(10.8)$ \\
\hline Female sex, $\mathrm{n}(\%)^{\mathrm{a}}$ & $2,668(79.1)$ & $1,448(80.5)$ \\
\hline \multicolumn{3}{|l|}{ Race, $\mathrm{n}(\%)^{\mathrm{a}}$} \\
\hline White & $3,119(92.5)$ & $1,672(93.0)$ \\
\hline Black & $60(1.8)$ & $38(2.1)$ \\
\hline Other/multiple & $151(4.5)$ & $71(4.0)$ \\
\hline \multicolumn{3}{|l|}{ Employment, $n(\%)^{a}$} \\
\hline Full-time & $999(31.4)$ & $623(34.8)$ \\
\hline Part-time & $339(10.7)$ & $199(11.1)$ \\
\hline Not employed & $1,840(57.9)$ & $876(48.9)$ \\
\hline Health insurance, $n(\%)^{a}$ & $3,130(98.6)$ & $1,680(93.8)$ \\
\hline \multicolumn{3}{|l|}{ Marital status, n (\%) } \\
\hline Married/cohabitating & $2,301(68.3)$ & $1,235(68.7)$ \\
\hline Divorced/separated/widowed & $524(15.5)$ & $270(15.0)$ \\
\hline Never married & $331(9.8)$ & $187(10.4)$ \\
\hline \multicolumn{3}{|l|}{ Primary caregiver, n (\%) } \\
\hline Yes & $2,445(72.8)$ & $1,306(73.0)$ \\
\hline If yes, spouse/partner & $2,158(88.7)$ & $1,157(89.0)$ \\
\hline Another family member & $223(9.2)$ & $115(8.9)$ \\
\hline Friend & $51(2.1)$ & $28(2.2)$ \\
\hline Smoking every day, $\mathrm{n}(\%)^{\mathrm{a}}$ & $187(5.9)$ & $78(4.4)$ \\
\hline MS duration, mean (SD), $y^{a}$ & $16.6(9.8)$ & $15.5(9.1)$ \\
\hline \multicolumn{3}{|l|}{ Current MS type, n (\%) } \\
\hline RRMS & $2,035(60.5)$ & $1,281(71.3)$ \\
\hline Progressive MS & $930(27.6)$ & $349(19.4)$ \\
\hline CIS and unknown & $401(11.9)$ & $168(9.3)$ \\
\hline Progression in prior $6 \mathrm{mo}, \mathrm{n}(\%)^{\mathrm{a}}$ & $1,047(31.4)$ & $471(26.4)$ \\
\hline \multicolumn{3}{|l|}{ Disability, n (\%) } \\
\hline Median PDDS score (IQR) & $3(1-5)$ & $3(1-4)$ \\
\hline PDDS score 0 , normal & $636(18.9)$ & $385(21.4)$ \\
\hline PDDS score 1, mild disability & $543(16.1)$ & $315(17.5)$ \\
\hline PDDS score 2 , moderate disability & $291(8.6)$ & $156(8.7)$ \\
\hline PDDS score 3 , gait disability & $478(14.2)$ & $278(15.5)$ \\
\hline PDDS score 4, early cane & $465(13.8)$ & $260(14.5)$ \\
\hline PDDS score 5, late cane & $327(9.7)$ & $158(8.8)$ \\
\hline PDDS score 6, bilateral support & $349(10.1)$ & $155(8.6)$ \\
\hline
\end{tabular}

Table Respondent sociodemographic and disease characteristics (continued)

\begin{tabular}{lll}
\hline Characteristics & All & DMT current \\
\hline PDDS score 7, wheelchair/scooter & $271(8.0)$ & $90(5.0)$ \\
\hline PDDS score 8, bedridden & $11(0.3)$ & $1(0.1)$ \\
\hline${\text { Current DMT, } \mathbf{n}(\%)^{\mathbf{c}}}$ & $1798(53.3)$ \\
\hline${\text { Interferon } \boldsymbol{\beta}-\mathbf{1}^{\mathbf{d}}}$ & $391(21.7)$ \\
\hline Glatiramer acetate & $408(22.7)$ \\
\hline Teriflunomide & $112(6.2)$ \\
\hline Fingolimod & $256(14.2)$ \\
\hline Dimethyl fumarate & $391(21.7)$ \\
\hline Natalizumab & $202(11.2)$ \\
\hline
\end{tabular}

Abbreviations: $\mathrm{CIS}=$ clinically isolated syndrome; DMT = disease-modifying therapy; IQR = interquartile range; MS = multiple sclerosis; PDDS = Patient Determined Disease Steps; RRMS = relapsing-remitting multiple sclerosis.

a $p<0.05$ for group comparison.

b Progression in prior 6 months: "Over the last 6 months, have your MS symptoms worsened in a gradual, progressive manner (not due to relapses or exacerbations)? Yes/No/Unsure."

c Percent may total $>100 \%$ because participants may have indicated $>1$ current DMT.

${ }^{\mathrm{d}}$ Interferon beta-1a and $-1 \mathrm{~b}$ and peginterferon beta- $1 \mathrm{a}$.

were spouses $(75 \%) ; 96 \%$ were white; $50 \%$ were female; and their mean age was 60 years. The main themes that emerged from the focus groups were risk of adverse events, quality of life, status of their MS, involvement of care partners, and decision making control.

Figure 2 Survey CONSORT diagram

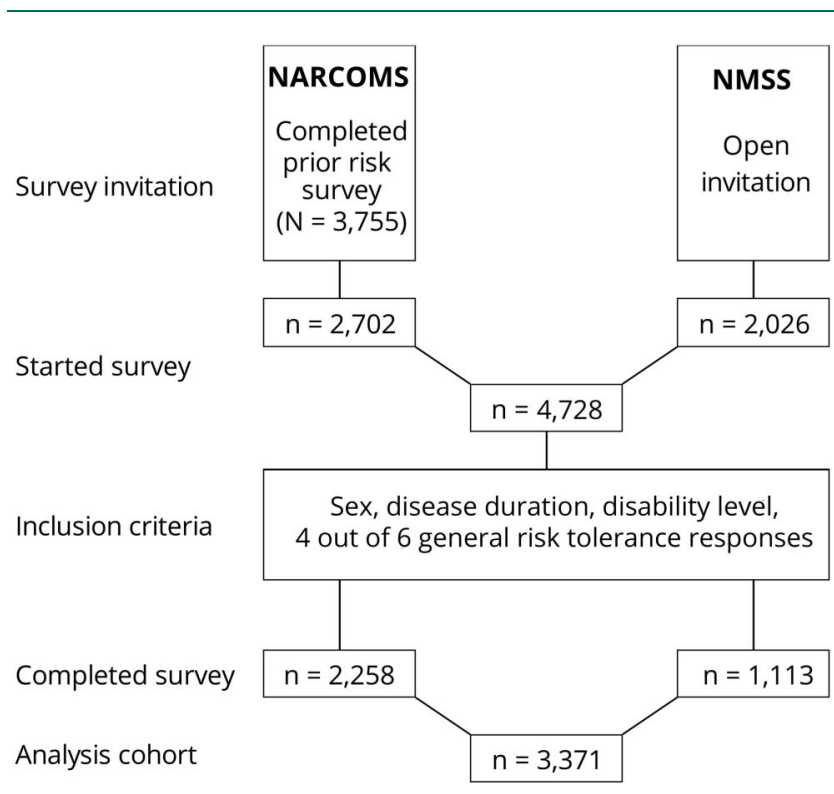

A Consolidated Standards in Reporting Trials (CONSORT) diagram of survey invitation through the North American Research Committee on Multiple Sclerosis (NARCOMS) Registry and National Multiple Sclerosis Society (NMSS) website, participants who initiated the survey, and analysis cohort. 


\section{Participant characteristics}

The survey was successfully completed by 3,171 participants (figure 2). The table summarizes participant characteristics and disease status. Overall, $79 \%$ of the survey participants were female, $92.5 \%$ were white, mean age was $55.1( \pm 11.1)$ years, and mean disease duration was $16.6( \pm 9.8)$ years. A large proportion of the participants (71.5\%) reported lower levels of disability (PDDS score $0-4$ ), and only $0.3 \%$ of the participants reported to be bedridden (PDDS score 8). In all analyses PDDS scores 7 and 8 were combined. Almost all participants reported having health insurance, and a large proportion of the participants (88.7\%) reported having a spouse/partner to assist in caregiving. About half the participants reported current use of DMT (53.3\%) with similar proportions on oral (22.1\%) and injectable (22.9\%) DMTs and only $8.6 \%$ on infusion therapies (table). About $10 \%$ of the participants reported to have never used any DMTs for their MS treatment.

\section{Overall RT}

Participants reported the highest tolerance for infection or thyroid complications (median RT 1:1,000 for both, figure 3 and table e-2 available from Dryad, doi.org/10.5061/dryad. $\operatorname{tg} 142 \mathrm{pt})$. The next highest tolerance was for skin rash (1: $2,000)$, followed by liver injury $(1: 10,000)$. The lowest RT was for both kidney injury and PML at 1:1,000,000.

\section{Unadjusted associations}

Unadjusted median risk was compared for sex, age groups (<41, 41-50, 51-60, 61-70, $\geq 71$ years), current disability, DMT history (current or past) of use, and, if currently taking a DMT, by type of DMT (injectable, oral, infusion) (table e-1 available from Dryad, doi.org/10.5061/dryad.tg142pt).

\section{By sex}

Male participants reported a high tolerance $(1: 1,000)$ to all complications except kidney injury $(1: 50,000)$ and PML $(1: 100,000)$. For all 6 risk complications, female participants consistently reported 2- to 20-fold lower RT (figure 4A and table e-1 available from Dryad, doi.org/10.5061/dryad. tg142pt). Female participants reported an RT of 1:2,000 for both infection and thyroid injury (2-fold lower than male participants), while the RT for both kidney injury and PML for the female participants was 1:1,000,000 (20- and 10-fold lower).

\section{By age}

Tolerance for liver injury, kidney injury, and PML decreased with age, whereas the RTs for infection, skin rash, and thyroid injury were not significantly different across age groups (figure 4B and table e-1 available from Dryad, doi.org/10.5061/dryad. $\operatorname{tg} 142 \mathrm{pt})$. Participants who were $<41$ years of age reported an RT of 1:2,000 for liver injury, while the rest of the age group reported an RT of 1:10,000. The tolerance pattern to kidney

Figure 3 Overall RT by various risks

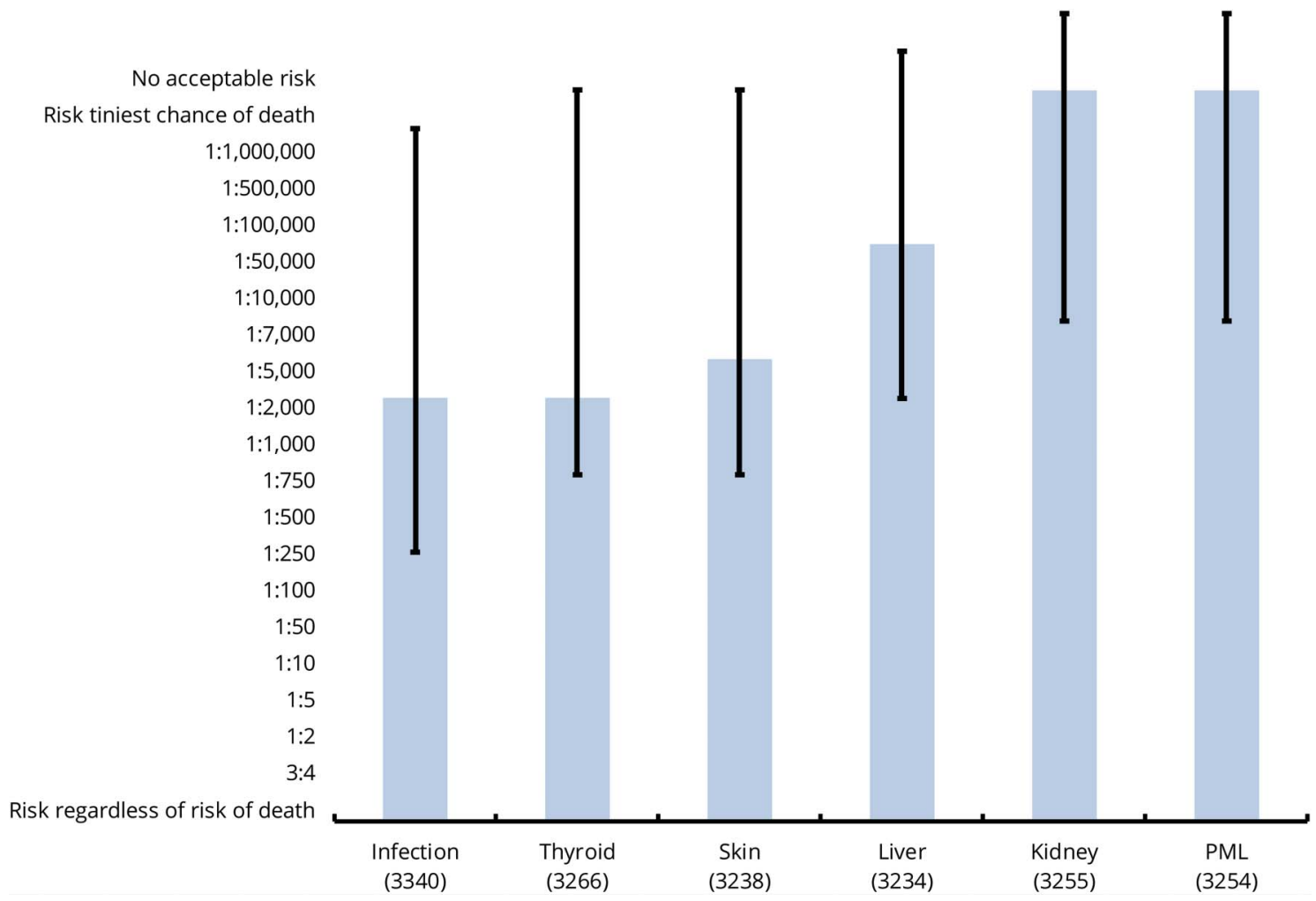

Median risk tolerance (RT) for each of the risk scenarios is indicated by solid bars; 25 th and 75 th percentiles of RTs are indicated by capped lines. PML = progressive multifocal leukoencephalopathy. 
Figure 4 Unadjusted association of median RT to participant characteristics

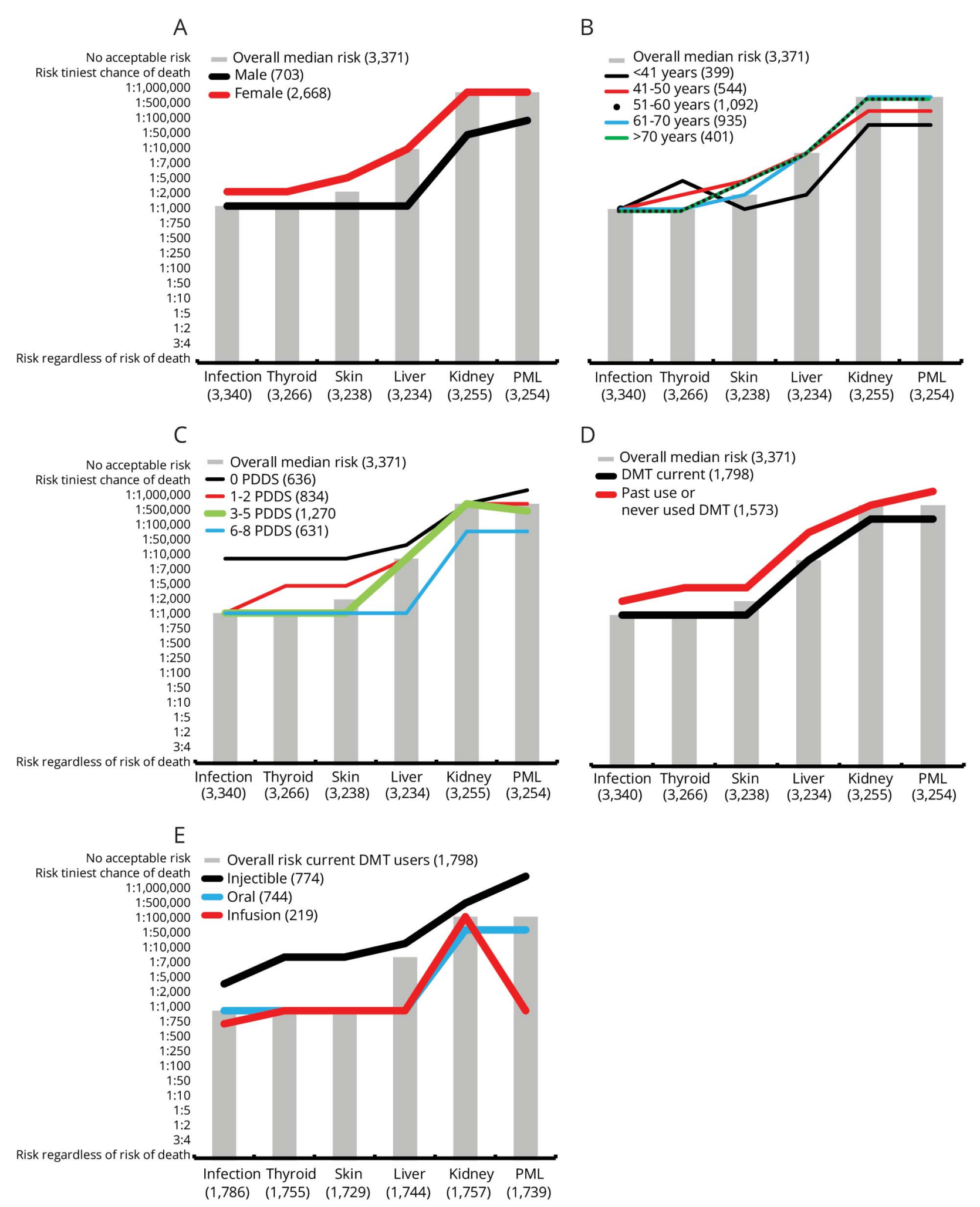

Median risk tolerance (RT) by (A) sex, (B) age, (C) Patient Determined Disease Steps, (D) disease-modifying therapy (DMT) use, and (E) DMT type. In all, the overall median RT is indicated by gray bars, and lines indicate median RT by participant characteristics. PML = progressive multifocal leukoencephalopathy.

injury and PML followed a similar pattern, with participants $<41$ years of age having a high RT of 1:100,000 and those $>51$ years of age having a low RT of 1:1,000,000.

\section{By disability}

In general, RT increased with disability, with higher levels of disability accepting significantly higher levels of risk compared 


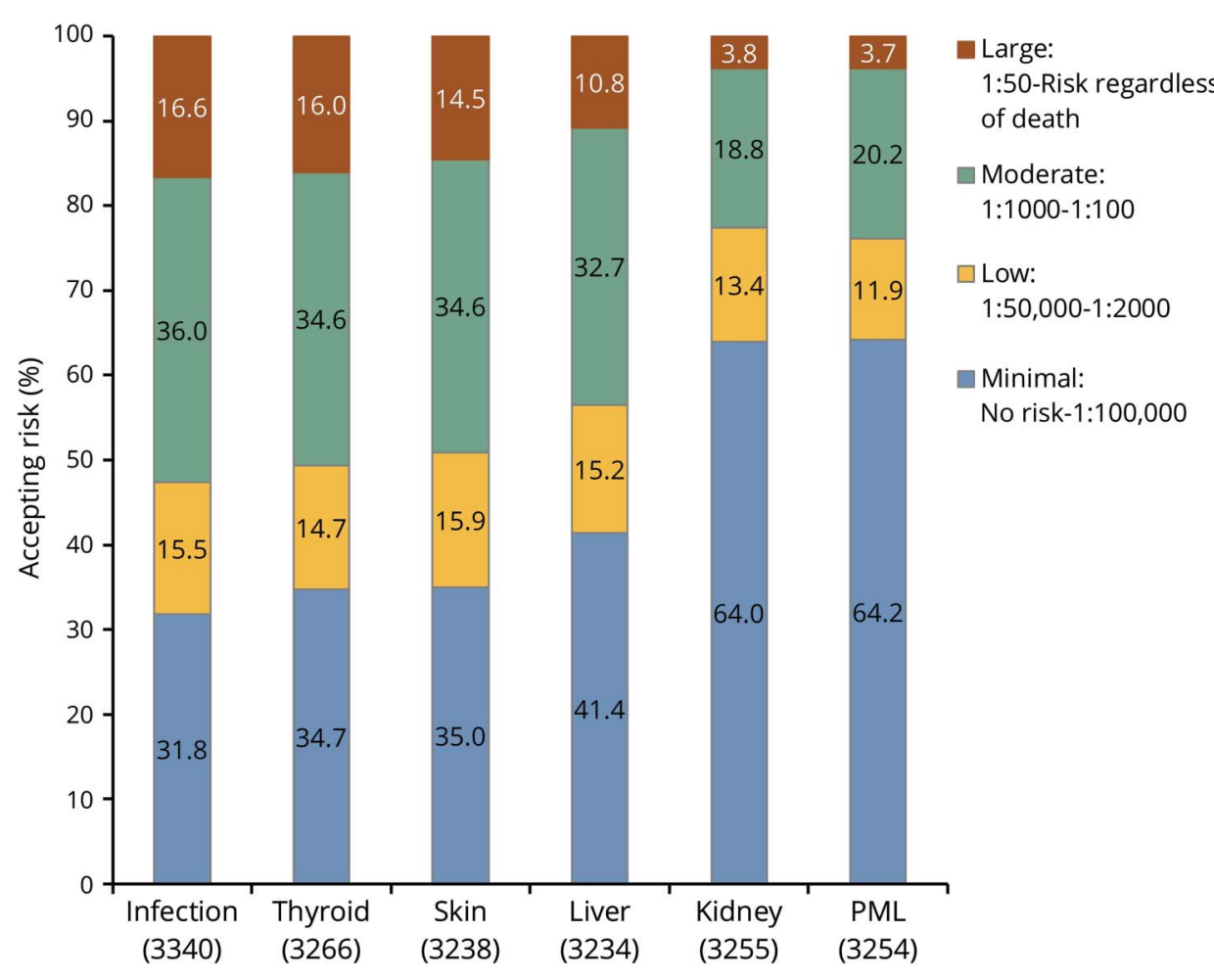

Graph illustrates percent accepting risks for each of the 6 scenarios when risk tolerance (RT) is stratified into 4 groups of increasing RT values: minimal, low, moderate, and large. $\mathrm{PML}=$ progressive multifocal leukoencephalopathy.

to a lower PDDS level across all 6 risk scenarios (figure 4C). In general, participants who reported minimal or no disability (PDDS score 0) had the least tolerance to all risks, and participants who reported a PDDS score $\geq 6$ had the highest tolerance to all risks. Those with PDDS scores of 1 to 2 and 3 to 5 had similar RTs for infection, skin rash, and liver injury; those with PDDS scores of 0 and 1 to 2 had similar RTs for skin, liver, and PML (table e-3 available from Dryad, doi.org/ $10.5061 /$ dryad.tg142pt).

\section{By DMT history}

Current DMT users exhibited 2- to 10-fold higher RTs than those not currently taking any DMT for their MS treatment (figure 4D). RT to infection, liver injury and PML risks appeared to be significantly higher $(p<0.0001)$ in current DMT users. The difference observed in the RT to thyroid injury and skin rash was not statistically significant.

\section{By type of current DMT use}

The tolerance within current DMT users was further examined on the basis of DMT type (injectables, orals or infusion). Of current DMT users $(n=1,798)$, there was a similar proportion of injectable (43.0\%) and oral (41.4\%) users and a smaller proportion who were on infusion therapies (12.2\%). Participants who were on injectable DMTs had the least tolerance to all 6 risk scenarios, and participants who were on infusion DMTs had the highest RT (figure 4E). Participants using injectable DMTs were very unlikely to accept PML risks (will not accept any risk), whereas those using infusion DMTs were quite tolerant of PML $(\mathrm{RT}=1: 1,000)$. Those taking infusion DMTs were the only participants who regarded risk of kidney injury (RT 1:500,000) to be higher than that of PML (RT 1:1,000, table e-1 available from Dryad, doi. org/10.5061/dryad.tg142pt); all other participants reported kidney injury risk to be either the same as that for PML or 2-fold lower.

\section{Other characteristics}

Neither disease duration nor smoking was associated with RT in any of the risk scenarios (table e-1 available from Dryad, doi.org/10.5061/dryad.tg142pt).

\section{Adjusted risk models}

The proportion of participants in each RT category (willingness to accept large, moderate, low, or minimal risk) for each condition is shown in figure 5. For infection, thyroid, skin, and liver, the conclusions for the adjusted models were similar to the unadjusted associations: men, older individuals, those with higher disability levels, and current DMT users were more willing to accept a larger amount of risk. For kidney and PML, nearly two-thirds of participants were willing to accept only minimal RT. Therefore, adjusted models looked at minimal vs higher RT and were similar to unadjusted results: men, older individuals, those with higher disability levels, and current DMT users were more willing to accept a larger amount of risk (data not shown). 


\section{Discussion}

We explored the views of people living with MS regarding their tolerance to various real-world risks associated with currently available therapies. We used a hypothetical therapy with a fixed realistic benefit and varied the complication to characterize RT associated with 6 different complications: infection, thyroid, skin, liver, kidney, and PML.

Participants exhibited highest tolerance for infection and thyroid injury (RT 1:1,000 for both) and the least tolerance for kidney injury and PML (1:1,000,000 for both, figure 2). Although RT was variable among people with MS, a large proportion were risk averse. Depending on the specific complication, $17 \%$ to $39 \%$ of the participants were unwilling to assume any risk for a beneficial therapy (indicated as "none" in table e-2, available from Dryad, doi.org/10.5061/ dryad.tg142pt). In contrast, $<2 \%$ of the participants were willing to accept any risk for the benefit of a therapy. An RT of 1:1,000 corresponds roughly to the midpoint in our risk tree (figure 1), and more than half the participants $(50 \%-76 \%)$ exhibited a median RT that was $<1: 1,000$.

For all RT scenarios, men were more tolerant to risks than women. In addition, increasing age was associated with lower RT. Specifically, older participants (age $>51$ years) reported lower tolerance to liver, kidney, and PML risks than participants who were $<41$ years old. Age of 41 to 50 years appeared to be a transition point in RT, with the median RT among participants $>50$ years of age remaining relatively stable. Greater disability was associated with greater RT in all scenarios. Participants with no disability (PDDS score 0 ) did not tolerate any PML risk, whereas those who were wheelchair bound or bedridden (PDDS score $>7$ ) had a median RT of 1:10,000 for PML. The shift in RT was most evident around PDDS score 5; participants with a PDDS score $\geq 6$ had a significantly higher tolerance to all risks compared to those with lower PDDS levels (table e-3 available from Dryad, doi.org/10.5061/dryad.tg142pt). About half of the participants reported current DMT use and exhibited greater $\mathrm{RT}$ in all scenarios. Willingness to accept risks was also influenced by DMT type. Participants taking oral and infusion DMTs reported a greater RT compared to those using injectables in all scenarios. Oral and infusion DMT users had similar RTs except for PML risk, for which participants taking infusion DMTs had a greater tolerance.

About two-thirds of the participants in this study also participated in a similar RT survey administered through NARCOMS in 2010 to $2011 .^{11}$ The earlier survey used the same treatment benefit (50\% reduction in relapse rate and 30\% slowing in disability progression) and assessed RT to the risk of PML. The median RT for PML in the earlier survey was 1 : 10,000 , much lower than in this study. The reason for this shift in RT over time is unclear but may be related to new perceptions regarding PML. In addition, the earlier survey assessed only PML risk, whereas in this survey, we have included 5 additional risk scenarios with the same therapeutic benefit. Thus, contextual effects from assessing PML risk along with other less serious risks such as skin rash or thyroid dysfunction may have shifted the PML RT.

Only a few other studies have evaluated RT in people with MS. One study surveyed 651 people with MS using the stated choice method for 3 different scenarios (PML, liver failure, and leukemia) and found the lowest RT to PML, followed by liver failure and leukemia. Our results parallel the study findings of low tolerance to PML followed by liver injury. ${ }^{9}$ Another study used the standard gamble paradigm to evaluate $\mathrm{RT}$ to death. ${ }^{15}$ Those investigators observed male sex, greater disability, and longer disease duration to be associated with greater tolerance to risk of death. We found a similar association with sex and disability but not disease duration. That study was relatively small $(\mathrm{n}=223)$ and focused on an urban MS specialty center, whereas our study was larger, included participants from across the United States, and more closely approximates the typical MS patient population.

There are several limitations to this study. We used a fixed benefit of therapy: 50\% reduction in relapse rate and 30\% slowing in disability. While this benefit represents a realistic estimate for an MS DMT, it is likely that RT to the same benefits may vary according to treatment benefit. Although 6 of the most commonly associated risk scenarios were studies, many other risks were not assessed. In some of our analyses, we combined DMTs by administration route, which may be an oversimplification because some DMTs with the same administration route likely have somewhat different efficacies (i.e., oral DMTs).

Guiding people with MS to the best treatment for them requires not only an assessment of the benefits and risks of a treatment but also an awareness of their preferences regarding which risks are considered acceptable. This study provides a detailed understanding of how different real-world risks are perceived by people living with MS and outlines some factors that are associated with these risks. Our findings indicate that RT differs according to sex, age, disability level, and current DMTs; therefore, treatment preferences across these characteristics also are likely to be different. At the same time, there was very broad RT within any individual sex, age, disability level, and current DMT, which highlights the heterogeneity of RT. Understanding risk perception and RT, as well as its heterogeneity, can ultimately lead to greater satisfaction with treatment choices and perhaps treatment adherence.

\section{Study funding}

This study was funded by grants from the NMSS (HC141102010 and RG 4778-A-6). NARCOMS is a project of the Consortium of MS Centers.

\section{Disclosure}

R. Fox has received consultant fees from Biogen Idec, GlaxoSmithKline, Novartis, Mallinckrodt, Acterlion, EMD 
Serono, Genentech, Teva, Xenoport, and Apitope, as well as grant and research support from Novartis. C. Cosenza, L. Cripps, P. Ford, M. Mercer, S. Natarajan, A. Salter, and T. Tyry report no disclosures relevant to the manuscript. S. Cofield has received consulting fees from the American Shoulder and Elbow Society and Oxford University Press, grant support from Pfizer and the American College of Rheumatology, and Data Safety Monitoring Board service fees from MedImmune, Inc. Go to Neurology.org/ $\mathrm{N}$ for full disclosures.

\section{Publication history}

Received by Neurology August 9, 2018. Accepted in final form November 27, 2018.

\section{Appendix Authors}

\begin{tabular}{|c|c|c|}
\hline Author & Location & Contribution \\
\hline $\begin{array}{l}\text { Robert } \\
\text { Fox }\end{array}$ & Cleveland Clinic, $\mathrm{OH}$ & $\begin{array}{l}\text { Principal investigator: obtained } \\
\text { grant, overall study design, } \\
\text { oversaw focus group } \\
\text { administration, survey design, } \\
\text { data analysis, manuscript } \\
\text { preparation }\end{array}$ \\
\hline $\begin{array}{l}\text { Carol } \\
\text { Cosenza }\end{array}$ & $\begin{array}{l}\text { University of } \\
\text { Massachusetts, Boston }\end{array}$ & $\begin{array}{l}\text { Survey design, survey testing } \\
\text { and revision, manuscript } \\
\text { preparation }\end{array}$ \\
\hline $\begin{array}{l}\text { Lauren } \\
\text { Cripps }\end{array}$ & $\begin{array}{l}\text { University of } \\
\text { Massachusetts, Boston }\end{array}$ & $\begin{array}{l}\text { Survey testing, manuscript } \\
\text { preparation }\end{array}$ \\
\hline Paul Ford & Cleveland Clinic, $\mathrm{OH}$ & $\begin{array}{l}\text { Grant writing, focus group } \\
\text { administration, data analysis of } \\
\text { focus group, survey design, } \\
\text { manuscript preparation }\end{array}$ \\
\hline $\begin{array}{l}\text { MaryBeth } \\
\text { Mercer }\end{array}$ & Cleveland Clinic, $\mathrm{OH}$ & $\begin{array}{l}\text { Focus group administration, } \\
\text { data analysis of focus group, } \\
\text { survey design, manuscript } \\
\text { preparation }\end{array}$ \\
\hline $\begin{array}{l}\text { Sneha } \\
\text { Natarajan }\end{array}$ & Cleveland Clinic, $\mathrm{OH}$ & $\begin{array}{l}\text { Grant writing, survey design, } \\
\text { data analysis, manuscript } \\
\text { preparation }\end{array}$ \\
\hline $\begin{array}{l}\text { Amber } \\
\text { Salter }\end{array}$ & $\begin{array}{l}\text { Washington University } \\
\text { School of Medicine, St. } \\
\text { Louis, MO }\end{array}$ & $\begin{array}{l}\text { Data analysis, manuscript } \\
\text { preparation }\end{array}$ \\
\hline Tuula Tyry & $\begin{array}{l}\text { St. Joseph's Hospital and } \\
\text { Medical Center, } \\
\text { Phoenix, AZ }\end{array}$ & $\begin{array}{l}\text { NARCOMS administration, } \\
\text { survey design, data analysis, } \\
\text { manuscript preparation }\end{array}$ \\
\hline $\begin{array}{l}\text { Stacey } \\
\text { Cofield }\end{array}$ & $\begin{array}{l}\text { University of Alabama, } \\
\text { Birmingham }\end{array}$ & $\begin{array}{l}\text { Survey design, survey } \\
\text { administration, data clean up, } \\
\text { data analysis, statistical analysis, } \\
\text { manuscript preparation }\end{array}$ \\
\hline
\end{tabular}

\section{References}

1. Weinshenker BG, Bass B, Rice GPA, et al. The natural history of multiple sclerosis: a geographically based study, I: clinical course and disability. Brain 1989;112 133-146.

2. Buck D, Hemmer B. Treatment of multiple sclerosis: current concepts and future perspectives. J Neurol 2011;258:1747-1762.

3. Duddy M, Haghikia A, Cocco E, et al. Managing MS in a changing treatment landscape. J Neurol 2011;258:728-739.

4. Polman CH, O'Connor PW, Havrdova E, et al. A randomized, placebo-controlled trial of natalizumab for relapsing multiple sclerosis. N Engl J Med 2006;354:899-910.

5. Kleinschmidt-DeMasters BK, Tyler KL. Progressive multifocal leukoencephalopathy complicating treatment with natalizumab and interferon beta-1a for multiple sclerosis. N Engl J Med 2005;353:369-374.

6. Langer-Gould A, Atlas SW, Green AJ, Bollen AW, Pelletier D. Progressive multifocal leukoencephalopathy in a patient treated with natalizumab. N Engl J Med 2005;353: 375-381.

7. Yousry TA, Major EO, Ryschkewitsch C, et al. Evaluation of patients treated with natalizumab for progressive multifocal leukoencephalopathy. N Engl J Med 2006;354: 924-933.

8. Stüve O, Marra CM, Jerome KR, et al. Immune surveillance in multiple sclerosis patients treated with natalizumab. Ann Neurol 2006;59:743-747.

9. Johnson FR, Van Houtven G, Ozdemir S, et al. Multiple sclerosis patients' benefit-risk preferences: serious adverse event risks versus treatment efficacy. J Neurol 2009;256: 554-562.

10. Heesen C, Kleiter I, Nguyen F, et al. Risk perception in natalizumab-treated multiple sclerosis patients and their neurologists. Mult Scler 2010;16:1507-1512.

11. Fox RJ, Salter A, Alster JM, et al. Risk tolerance to MS therapies: survey results from the NARCOMS registry. Mult Scler Relat Disord 2015;4:241-249.

12. Bennett KJ, Torrance GW. Measuring health state preferences and utilities: Rating scale, time trade-off, and standard gamble techniques. In: Quality of Life and Pharmocoeconomics in Clinical Trials. 2nd ed. Philadelphia: Lippincott-Raven Publishers; 1996:253-265.

13. Kattan MW. Comparing treatment outcomes using utility assessment for healthrelated quality of life. Oncology 2003;17:1687-1701.

14. Hohol MJ, Orav EJ, Weiner HL. Disease steps in multiple sclerosis: a longitudinal study comparing disease steps and EDSS to evaluate disease progression. Mult Scler 1999;5:349-354.

15. Glanz BI, Greeke E, LaRussa A, et al. Risk attitudes and risk perceptions in individuals with multiple sclerosis. Mult Scler J Exp Transl Clin 2016;2:2055217316665406. 


\title{
Neurology
}

\author{
A survey of risk tolerance to multiple sclerosis therapies \\ Robert J. Fox, Carol Cosenza, Lauren Cripps, et al.
}

Neurology 2019;92;e1634-e1642 Published Online before print March 13, 2019

DOI 10.1212/WNL.0000000000007245

This information is current as of March 13, 2019

\section{Updated Information \& Services}

References

Citations

Subspecialty Collections

Permissions \& Licensing

Reprints including high resolution figures, can be found at: http://n.neurology.org/content/92/14/e1634.full

This article cites 14 articles, 0 of which you can access for free at: http://n.neurology.org/content/92/14/e1634.full\#ref-list-1

This article has been cited by 2 HighWire-hosted articles: http://n.neurology.org/content/92/14/e1634.full\#\#otherarticles

This article, along with others on similar topics, appears in the following collection(s):

\section{Burden of disease}

http://n.neurology.org/cgi/collection/burden_of_disease

Decision analysis

http://n.neurology.org/cgi/collection/decision_analysis

Multiple sclerosis

http://n.neurology.org/cgi/collection/multiple_sclerosis

Information about reproducing this article in parts (figures,tables) or in its entirety can be found online at:

http://www.neurology.org/about/about_the_journal\#permissions

Information about ordering reprints can be found online:

http://n.neurology.org/subscribers/advertise

Neurology ${ }^{\circledR}$ is the official journal of the American Academy of Neurology. Published continuously since 1951, it is now a weekly with 48 issues per year. Copyright Copyright ( 2019 The Author(s). Published by Wolters Kluwer Health, Inc. on behalf of the American Academy of Neurology.. All rights reserved. Print ISSN: 0028-3878. Online ISSN: 1526-632X.

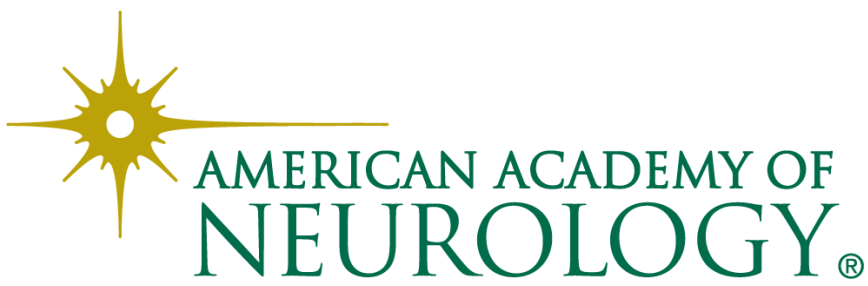

